\title{
PATTERNS OF CORONARY DOMINANCE IN PATIENTS UNDERGOING CORONARY ANGIOGRAPHY
}

\author{
Khatun $S^{1^{*}}$, Nepal $R^{2}$, Yadav $R K^{1}$
}

\begin{abstract}
Affiliation
1 Lecturer, Department of Anatomy, Nobel Medical College and Teaching Hospital, Biratnagar, Nepal.

2. Associate Professor, Department of Cardiology, Nobel Medical College and Teaching Hospital, Biratnagar, Nepal.
\end{abstract}

\section{ARTICLE INFO}

Received : 23 November, 2019

Accepted : 26 December, 2019

Published : 31 December, 2019

C. Authors retain copyright and grant the journal right of first publication with the work simultaneously licensed under Creative Commons Attribution License CC - BY 4.0 that allows others to share the work with an acknowledgment of the work's authorship and initial publication in this journal.

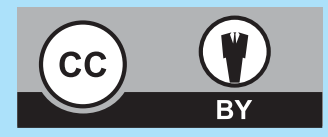

\section{ORA 148}

DOI: http://dx.doi.org/10.3126/bjhs.v4i3.27043

\author{
* Corresponding Author \\ Dr. Sanzida Khatun \\ Lecturer \\ Department of Anatomy \\ Nobel Medical College, Biratnagar, Nepal. \\ Email: ksanzida12@gmail.com \\ ORCID ID: https://orcid.org/0000-0002-0037-0509
}

\section{ABSTRACT}

\section{Introduction}

Right and left coronary arteries supply the heart. The dominant vessel supplies posterior descending artery and at least one posterolateral branch to inferior surface of heart. The coronary circulation can be: right dominant, left dominant and co-dominant.

\section{Objective}

The aim of this study was to determine the different patterns of coronary artery dominance in patients with coronary artery disease.

\section{Methodology}

A descriptive cross-sectional study was conducted in patients undergoing coronary angiography in cathlab of Nobel Medical College and Teaching Hospital, Biratnagar, Nepal. The coronary angiography was taken from all standard views. For assessing the left dominance, left anterior oblique cranial view was specially focused.

\section{Result}

There were $72.9 \%$ right dominant, $22.2 \%$ left dominant and $4.9 \%$ co-dominant cases. Both sexes had similar patterns of coronary dominance $(73.8 \% \mathrm{RD}, 22.2 \% \mathrm{LD}$ and $4.0 \% \mathrm{CD}$ among males whereas, $71.4 \% \mathrm{RD}, 22.1 \% \mathrm{LD}$ and $6.5 \% \mathrm{CD}$ among females) as that in total study population. The highest number of patients was found in 60 to 69 years of age group. More number of patients had left dominance in less than 50 years age group than in 50 years and above group. There were no significant differences in pattern of coronary dominance with age groups.

\section{Conclusion}

The most prevalent type of coronary artery dominance is right dominant followed by left dominant and co-dominant.

\section{KEYWORDS}

Angiography, blood supply of heart, coronary artery, coronarydominance

\section{Citation}

Khatun S, Nepal R, Yadav RK. Patterns of Coronary Dominance in Patients Undergoing Coronary Angiography. BJHS 2019;4 (3)10:864-868. 


\section{INTRODUCTION}

The heart is supplied by right and left coronary arteries arising from the ascending aorta. The right coronary artery (RCA), arises from anterior aortic sinus of ascending aorta and the left coronary artery (LCA) arises from the left posterior aortic sinus. The RCA proceeds along the right side of the coronary sulcus and on reaching the diaphragmatic surface of heart it gives rise to posterior descending artery (PDA) in majority of the hearts. The LCA divides into anterior interventricular artery, which proceeds inferiorly through anterior interventricular sulcus, and left circumflex artery (LCX) which is directed to left part of the coronary sulcus and reaches to posterior aspect of the heart. On the basis of branches given by these arteries in posterior aspect of the ventricles of the heart, the coronary circulation can be divided into right dominant (RD), left dominant (LD) and codominant (CD). When the posterior descending artery and at least one posterolateral branches are supplied by right coronary artery it is called RD. When they are supplied by circumflex branch of left coronary artery, it is termed as LD which is the less balanced type of circulation. When PDA arises from RCA and posterolateral branches from LCx, it is called Co-dominant or balanced type of circulation. ${ }^{1}$

Coronary artery disease (CAD) has been one of the major causes of death in developed countries. But recently, deaths by $C A D$ are in declining phase in those countries due to awareness, advanced technologies and effective control by population based strategies of prevention. However, its incidence is increasing in developing countries rapidly due to less healthy life styles, industrialization and urbanization. ${ }^{2}$ In context of Nepal, the incidence of Myocardial Infarction (MI) started increasing rapidly in 1950 s and sixties. Although the data of incidence and prevalence of CAD is not available in national level, the hospital based data of Nepal show 40 fold rise in Acute Myocardial Infarction (AMI) in the last 30 years. ${ }^{3}$ Very few studies ${ }^{3-7}$ on anatomy of coronary circulation have been done in Nepal focusing on population of Kathmandu and hardly any similar study has been done in eastern region of Nepal. Knowledge regarding variation in anatomy of coronary artery and its pathology is important in reaching a diagnosis, planning treatment and improving prognosis of coronary artery diseases.

The aim of this study was to determine the different patterns of coronary artery dominance in patients with coronary artery disease presenting to the cathlab of a tertiary care hospital in eastern region of Nepal.

\section{METHODOLOGY}

A descriptive cross-sectional study was conducted in patients with coronary artery disease undergoing coronary angiography in Cathlab of Nobel Medical College and Teaching Hospital in Biratnagar, Nepal. The study period was from May, 2017 to December, 2018. The ethical approval (ref. no. 61/2017) was taken from IRC-NMCTH of Nobel Medical College. The subjects included patients above the age of 18 years indicated for coronary angiography. The patients showing entire proximal occlusion and patients with congenital anomalies were excluded from study group. A written consent was taken from the study group after providing them the information regarding the study.

Sample size was calculated using the standard formula for estimating population proportion for cross-sectional study. With $95 \%$ level of confidence, $5 \%$ prevalence of coronary artery disease as observed in another study performed in $\mathrm{Nepal}^{3}$ and 5 taken as absolute margin of error, the sample size derived was 72.99. However, the study was conducted in 203 patients.

The sampling method followed was convenient sampling method. The coronary angiography was taken from all standard views. The RCA or LCx was identified as dominant if its branches supplied PDA and at least one posterolateral branch to the inferior surface of the heart. They were recorded as RD and LD, respectively. When PDA was supplied from RCA and posterolateral branches from LCx, it was recorded as CD. ${ }^{1}$ For assessing the left dominance, left anterior oblique cranial view was specially focused. The pattern of coronary artery dominance, age and sex of the patients were recorded on proforma. The patients were divided into 5 age groups, less than 40 years, 40 to 49 years, 50 to 59 years, 60 to 69 years and 70 years and above to derive the frequencies of different coronary dominance patterns in each group.

The data analysis was done with statistical package for social sciences (SPSS) 16 software. The descriptive analysis of data was done to derive frequencies, percentages, mean and standard deviation.

\section{RESULT}

In this study, there were 203 patients aged 18 and above years consisting 126 (62.07\%) male and 77 (37.93\%) female. The age range of the study group was 30 to 94 with mean of $58.99( \pm 11.61)$.

Table 1: Coronary Dominance in both sexes and total
population
\begin{tabular}{|l|c|c|c|c|c|}
\hline \multirow{4}{*}{ Right Dominant } & 93 & $73.8 \%$ & 55 & $71.4 \%$ & $148(72.9 \%)$ \\
\cline { 2 - 7 } & \multicolumn{2}{|c|}{ Male } & \multicolumn{2}{c|}{ Female } & Total \\
\cline { 2 - 7 } & N & $\%$ & $n$ & $\%$ & $n(\%)$ \\
\hline Left Dominant & 28 & $22.2 \%$ & 17 & $22.1 \%$ & $45(22.2 \%)$ \\
\hline Co-dominant & 5 & $4.0 \%$ & 5 & $6.5 \%$ & $10(4.9 \%)$ \\
\hline Total & 126 & $100.0 \%$ & 77 & $100.0 \%$ & $203(100.0 \%)$ \\
\hline
\end{tabular}

There were 148 (72.9\%) cases with RD, 45 (22.2\%) with LD and $10(4.9 \%)$ with $C D$. Both sexes had similar pattern. Among the males, 93 (73.8\%) had RD, 28 (22.2\%) had LD and 5 (4.0\%) had CD. Whereas among the females, 55 (71.4\%) had RD, 17 (22.1\%) had LD and 5 (6.5\%) had CD. 


\begin{tabular}{|c|c|c|c|c|c|c|c|}
\hline \multirow[b]{3}{*}{ Age Group } & \multicolumn{6}{|c|}{ Coronary Dominance } & \multirow{3}{*}{$p$ value } \\
\hline & \multicolumn{2}{|c|}{ Right Dominant } & \multicolumn{2}{|c|}{ Left Dominant } & \multicolumn{2}{|c|}{ Co-dominant } & \\
\hline & Count & $\%$ & Count & $\%$ & Count & $\%$ & \\
\hline Less than 40 years & 5 & $62.5 \%$ & 3 & $37.5 \%$ & 0 & $0.0 \%$ & \multirow{5}{*}{0.094} \\
\hline 40 to 49 years & 18 & $56.2 \%$ & 11 & $34.4 \%$ & 3 & $9.4 \%$ & \\
\hline 50 to 59 years & 38 & $70.4 \%$ & 15 & $27.8 \%$ & 1 & $1.9 \%$ & \\
\hline 60 to 69 years & 48 & $76.2 \%$ & 10 & $15.9 \%$ & 5 & $7.9 \%$ & \\
\hline 70 years and above & 39 & $84.8 \%$ & 6 & $13.0 \%$ & 1 & $2.2 \%$ & \\
\hline
\end{tabular}

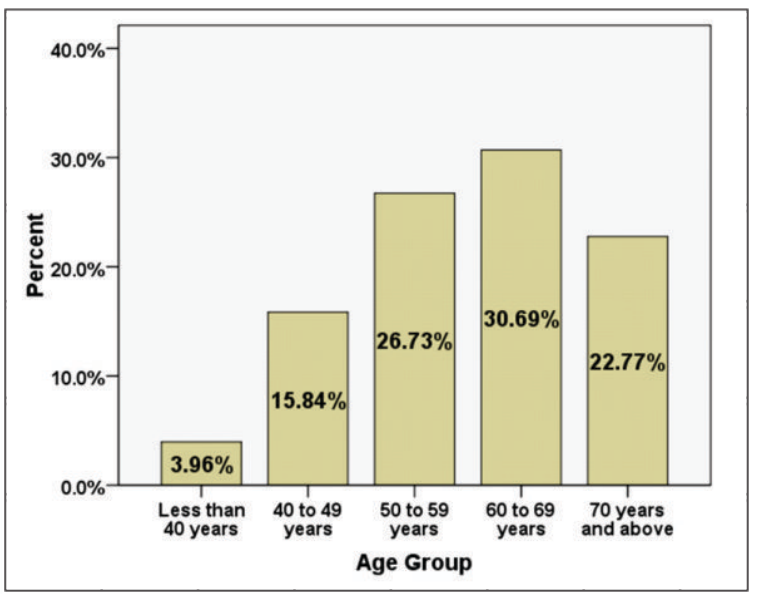

Figure 1: Bar diagram showing age groups of study population

There were $8(3.96 \%)$ patients in less than 40 years of age group, $32(15.84 \%)$ in 40 to 49 years of age group, 54 (26.73\%) in 50 to 59 years of age group, $63(30.69 \%)$ in 60 to 69 years of age group and $46(30.69 \%)$ patients in 70 and above years of age group. The highest number of patients was found in 60 to 69 years of age group, followed by 50 to 59 years of age group and 70 years and above group. However, comparatively more number of patients had LD in less than 50 years of age group in comparison to 50 and above years of age group. There were no significant differences in pattern of coronary dominance with age groups ( $p=0.094)$ as shown in Table 2 .

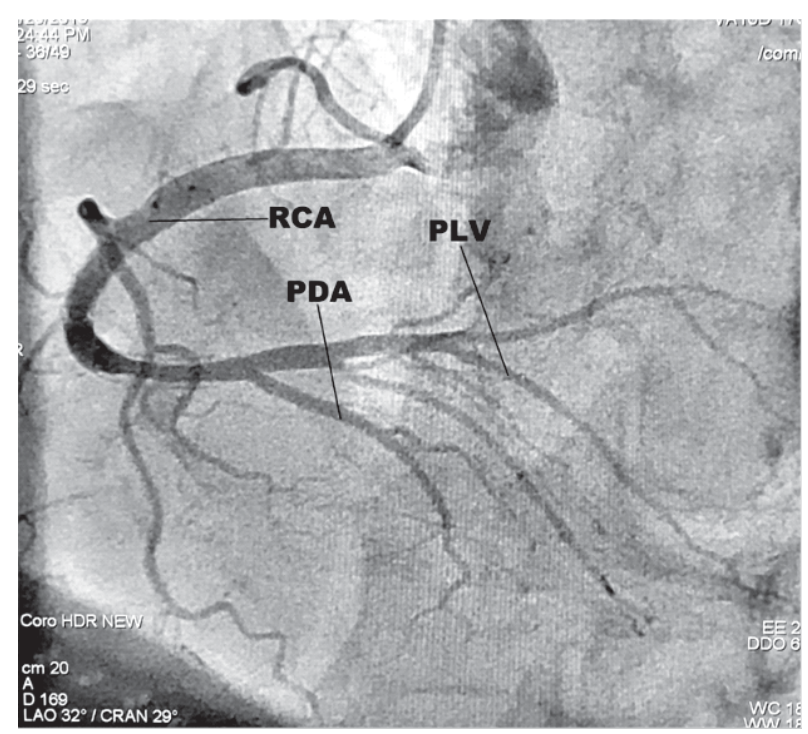

Figure 2: Angiogram showing Right Coronary Artery in Right Coronary Dominant Pattern. RCA - Right Coronary Artery, PDA - Posterior Descending Artery, PLV - Posterior Left Ventricular Artery.

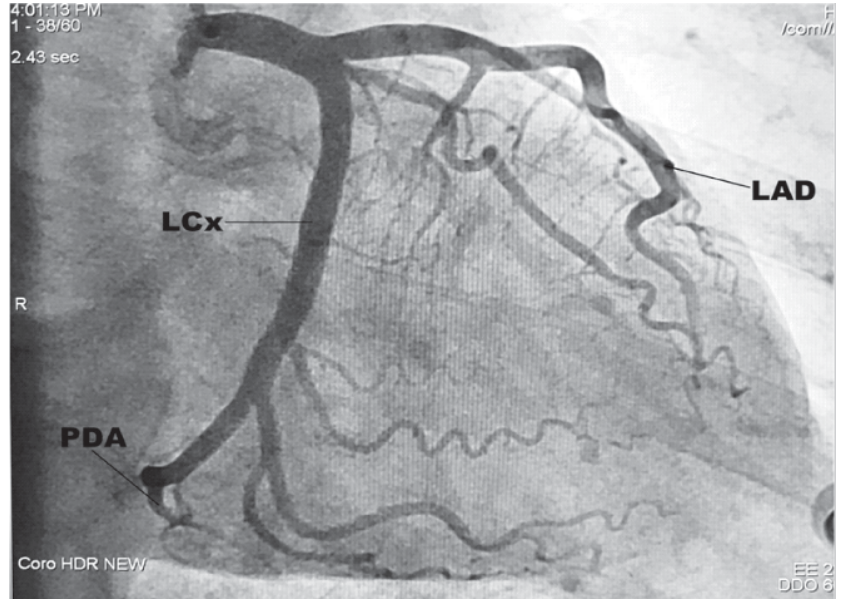

Figure 3: Angiogram showing Left Coronary Artery in Left Coronary Dominant Pattern. LCx-Left Circumflex Artery, PDA-Posterior Descending Artery, LAD - Left Anterior Descending Artery.

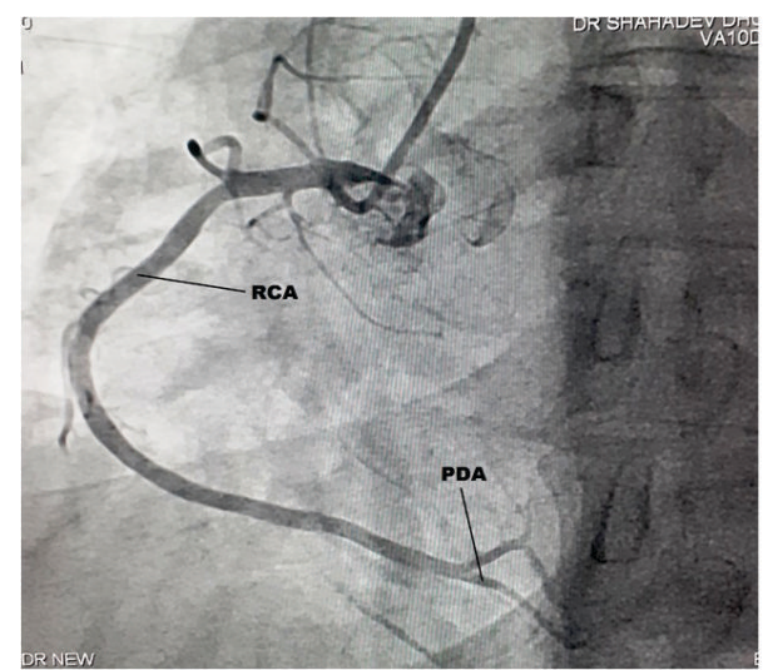

Figure 4: Angiogram showing Right Coronary Artery in Codominant Pattern. RCA-Right Coronary Artery, PDAPosterior Descending Artery.

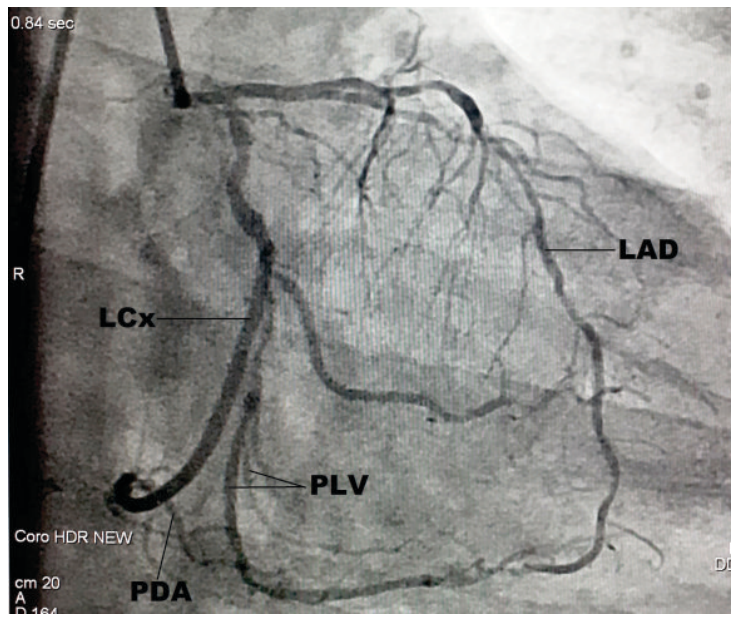

Figure 5: Angiogram showing Left Coronary Artery in Co-dominant Pattern. LCx - Left Circumflex Artery, LAD - Left Anterior Descending Artery, PDA - Posterior Descending Artery, PLV - Posterior Left Ventricular Artery (Posterolateral Branch)

\begin{tabular}{rrr} 
Birat Journal of Health Sciences & B 606 \\
\hline
\end{tabular}




\section{DISCUSSION}

The present study reports the pattern of coronary artery dominance in 203 patients aged 18 and above years with coronary artery disease in a tertiary care hospital in eastern region of Nepal. The dominance pattern was found to be similar in both sexes and all age groups (i.e. highest number of RD followed by LD and least number of CD).

In this study, it was observed that $72.9 \%$ of study group had RD, $22.2 \%$ had LD and $4.9 \%$ had CD. In some studies performed in Nepal, the pattern was similar. ${ }^{4,5}$ In a study by Karna AK, RD was found in $85.5 \%$, LD in $10.0 \%$ and CD in $4.5 \%$ cases. $^{4}$ In another study by Nepal R, there were $83.0 \%$ RD, $10.0 \%$ LD and $7.0 \%$ CD patients. ${ }^{5}$ However, in other studies performed in Nepal, more CD cases than LD were evident. ${ }^{6,7}$ A cadaveric study by Pradhan A revealed $85 \%$ RD, 5\% LD and 10\% CD subjects. ${ }^{6}$ In another study done in Gangalal Hospital in Kathmandu, $57 \%$ subjects had RD, $17 \%$ had LD and $26 \%$ had CD. ${ }^{7}$ In these studies, the percentage of LD was found to be lesser than in present study.

In a study by Aziz F, there was 60.5\% RD, 19.5\% LD and $20.0 \%$ $C D$, in which comparatively more percentage of LD was evident similar to our study. ${ }^{8}$ In a cadaveric study performed in Assam, the result exhibited similar finding with $70.00 \%$ RD, $18.57 \%$ LD and $11.43 \%$ CD. ${ }^{9}$ Similarly, in another study done in Pakistan, there was $60.45 \%$ RD, $15.00 \%$ LD and $24.50 \% \mathrm{CD}^{10}$ This result was consistent to the findings of Aziz F where CD cases were more than LD. The balanced type or $C D$ circulation has been associated with less risk of coronary heart disease. ${ }^{8}$

In contrast to our study, relatively fewer LD cases than ours were found in studies conducted in other countries by many other researchers like Fakhir $H A$, Khan MN, Prafulla $D$, Jaishree $H$, Goldberg A, Abdellah AA, Knaapen $M$ and Veltman CE. ${ }^{11-18}$ In Fakhir's study, there were $76.4 \% \mathrm{RD}$, $12.6 \% \mathrm{LD}$ and $10 \% \mathrm{CD}^{11}$ In the study by Khan MN, $84.9 \%$ of patients had RD, $11.3 \%$ had LD and $3.8 \%$ had $C D .{ }^{12}$ In another study, $88 \%$ were RD, $10 \%$ were LD and $2 \%$ were $C D .^{13}$ In another cadaveric study, the finding was $83 \% \mathrm{RD}, 14.5 \% \mathrm{LD}$ and $2.5 \% \mathrm{CD}^{14}{ }^{14}$ In a study conducted in Sudan, $77 \%$ of RD, $8 \%$ of LD and $15 \%$ of CD were observed. ${ }^{16}$ In Knaapen's study, there were $81.2 \%$ RD patients, 9.1\% LD patients and 9.7\% CD patients and there was decrease in the prevalence of $L D$ and CD with increasing age among the study group. ${ }^{17}$ In another study by Veltman, there were $88.14 \%$ RD, 9.19\% LD and $2.66 \% \mathrm{CD} .^{18}$ In these studies, the percentages of RD was close to $80 \%$, LD was near to $10 \%$ and CD or balanced types were less than $10 \%$.

Many researchers have suggested the relation of LD with coronary diseases and association of $C D$ with less risk of coronary heart diseases. ${ }^{4,15,18,19}$ In a study, $68.8 \%$ of LD population had abnormal ECG and $42.2 \%$ of RD had abnormal
ECG. ${ }^{4}$ In another study, association between presence of LD and increased mortality among coronary artery disease patients was observed. ${ }^{15}$ The coronary dominance has a role in relative contribution of the different coronary vessels to the total left ventricular blood flow. In another study conducted in Netherland, LD was identified as predictor for myocardial infarction and mortality. There was significantly increased risk of 30 days mortality and re infarction post ST segment elevation Myocardial Infarction (STEMI) suggesting negative role of LD on prognosis of coronary artery disease. ${ }^{18}$ In a study, the dominance was classified into 2 groups. Among total patients, $9.8 \%$ had LD and $90.2 \%$ were in nonLD group. More severe calcifications, more bifurcation lesions and more target vessel related Myocardial Infarction (MI) were observed in LD patients. Similarly, higher incidence of pre-procedural $\mathrm{Ml}$ was also observed. ${ }^{19}$ In contrast, a study done in Northern Chinese population revealed significantly higher proportion of serious coronary stenosis among patients with RD than among patients with LD and $\mathrm{CD}$. The study suggested association of RD with the severity of CAD. ${ }^{20}$ The present study, however, did not aim to assess the relation between coronary dominance and severity and outcome of coronary heart diseases. Nevertheless, in this study, increased number of patients with LD in younger age groups could suggest the relation of LD with early onset of coronary arterial disease symptoms. There were $37.5 \%$, $34.4 \%$ and $27.8 \%$ LD patients in less than 40 years, 40 to 49 years and 50 to 59 years of age groups, respectively, whereas only $15.9 \%$ and $13.0 \%$ in 60 to 69 years and above 70 years of age groups, respectively. In the other hand, increased number of RD patients was found in 50 years and above age groups than in age groups below 50 years.

\section{CONCLUSION}

The most prevalent type of coronary artery dominance is $\mathrm{RD}$. LD is less common and CD is the least prevalent. This study demonstrates that the patterns of coronary dominance in population of eastern Nepal is similar to various studies carried out at national and international level. However, few studies performed in Kathmandu contrast from the current findings which suggests that more studies are required to acquire population based patterns. The increased number of LD pattern in younger population is also to be noted, but future researches should be able to identify such element as a risk factor for early onset of CAD.

\section{LIMITATIONS OF THE STUDY}

This study was conducted in small number of patients for a period of one year using conventional angiographic method. The findings can be more useful if similar researches are conducted in larger population with modern techniques that show better views of the vessels. The study could also not predict the actual association of a particular type of dominance with occurrence and risks of coronary heart diseases. 


\section{RECOMMENDATIONS}

The future studies can be done in larger number of population to associate a particular type of coronary supply pattern with the occurrence of heart diseases. Similar studies should be carried out in different regions and groups considering the variation of pattern of coronary dominance depending on geography, ethnicity and race. Similar kind of studies can be conducted using different methods.

\section{ACKNOWLEDGEMENTS}

We acknowledge the guidance from Prof. S. A. C. Singh. We thank the department of Cardiology, Nobel Medical College, Biratnagar, Nepal for their support and co-operation.

\section{CONFLICT OF INTEREST}

None

\section{FINANCIAL DISCLOSURE}

None

\section{REFERENCES}

1. Libby P, Bonow RO, Mann DL, Zipes DP. Braunwald Heart Diseases: a text book of Cardiovascular Medicine 8th ed. Saunders 2008:478. Available from: Textbook

2. Gupta R, Mohan I, Narula J. Trends in coronary heart disease epidemiology in India. Annals of global health. 2016 Mar 1;82(2):30715.PMID: 27372534. DOI: 10.1016/j.aogh.2016.04.002.

3. Maskey A, Sayami A, Pandey MR. Coronary artery disease: an emerging epidemic in Nepal. J Nep Med Assoc. 2003;42(146):1224.DOI: 10.31729/jnma.807.

4. Karna AK, Maskey A, Nepal H, Yadav DN. Study of coronary artery dominance in Nepalese population by angiographic method. Nep Heart J. 2017 Nov 1;14(2):25-30.DOI: https://doi.org/10.3126/ njh.v14i2.18499.

5. Nepal R, Anil OM. Angiographic study of Coronary Artery Dominance in Nepalese Population. J Nobel Med Col. 2016 Sep 23;5(1):6-8.DOI: https://doi.org/10.3126/jonmc.v5i1.15746.

6. Pradhan A, Chalise U, Lama CP, Ghosh SK. A study of coronary dominance in the population of Kathmandu Valley. Nepal Med Coll J. 2018;20(1-3):28-32. Available from: https://www.nmcth.edu /images/gallery/NMCJ\%20Vol.\%2020\%20No.\%201-3\%20March/ June/September/Pradhan_A1.pdf

7. Dhakal A, Shrestha RN, Maskey A, Pandey S. Coronary artery dimensions in the Nepalese population. Journal of the Anatomical Society of India. 2015 Jun 1;64(1):27-31. DOI: https://doi.org/ 10.1016/j.jasi.2015.03.001

8. Mian FA, Malik SN, Ismail M, Khan IS, Kachlu AR, Rehman M,et al. Coronary Artery Dominance: What pattern exists in Pakistani Population?. Ann Pak Inst Med Sci. 2011;7(1):3-5.Available from https://apims.net/apims_old/Volumes/Vol7-1

9. Das H, Das G, Das DC, Talukdar K. A study of coronary dominance in the population of Assam. J Anat Soclnd. 2010 Dec 1;59(2):187-91. Available from http://medind.nic.in/jae/t10/i2/jaet10i2p187.pdf

10. Kaimkhani ZA, Ali MM, Faruqi AM. Pattern of coronary arterial distribution and its relation to coronary artery diameter. J Ayub Med Collabbottabad. 2005;17(1).PMID: 15929526.

11. Fakhir HA, Rgeeb AN, Gheni MN. Pattern of coronary artery dominancy by coronary angiography in Iraqi patients \& the relationship with coronary artery disease. J College of education. 2012(3):180-9.Available from https://www.iasj.net/iasj? func= fulltext\&ald $=63386$
12. Khan MN, Adil M, Shabbir M, Aziz S, Hamid S. Coronary Artery Dominance: Ct Angiographic Findings In 1000 Patients. Pak Armed Forces Med J. 2015;65.Available from https://pdfs.semanticscholar. org/154c/240249581127ce95e83883a3bac583447e4d.pdf

13. Prafulla D, Sandeep P. A Study Of Coronary Dominance In Population Of Jalgaon Region Of North Maharashtra By Angiographic Method. Int J Anat Res. 2015;3(2):1099-02.DOI: 10.16965/ijar.2015.160.

14. Jaishree $H$, Ashwini H. Study of coronary dominance in the population of Hyderabad Karnataka region. IJCRR. 2015 Oct 15;7(20):68.Available from http://www.ijcrr.com/uploads/415_pdf.pdf

15. Goldberg A, Southern DA, Galbraith PD, Traboulsi M, Knudtson ML, Ghali WA, et al. Coronary dominance and prognosis of patients with acute coronary syndrome. Am Heart J. 2007 Dec 1;154(6):111622.PMID: 18035084. DOI:10.1016/j.ahj.2007.07.041.

16. Abdellah AA, Elsayed AS, Hassan MA. Angiographic coronary artery anatomy in the Sudan Heart Centre. Khartoum Med J. 2012 Feb 2;2(1).Available from http://onlinejournals.uofk.edu/index.php/ $\mathrm{kmj} /$ article/download/414/1404

17. Knaapen M, Koch AH, Koch C, Koch KT, Li X, van Rooij PC, et al. Prevalence of left and balanced coronary arterial dominance decreases with increasing age of patients at autopsy. A postmortem coronary angiograms study. Cardiovascular Pathology. 2013 Jan 1;22(1):49-53.PMID: 22463919. DOI: 10.1016/j.carpath.2012.02.012.

18. Veltman CE, de Graaf FR, Schuijf JD, van Werkhoven JM, Jukema JW, Kaufmann PA, et al. Prognostic value of coronary vessel dominance in relation to significant coronary artery disease determined with noninvasive computed tomography coronary angiography. Euro Heart J. 2012 Mar 4;33(11):1367-77. DOI: 10.1093/eurheartj/ehs034.

19. Lam MK, Tandjung K, Sen H, Basalus MW, van Houwelingen KG, Stoel MG, Louwerenburg JW, Linssen GC, Said SA, Nienhuis MB, de Man FH. Coronary artery dominance and the risk of adverse clinical events following percutaneous coronary intervention: insights from the prospective, randomised TWENTE trial. Eurolntervention. 2015 Jun 1;11(2):180-7. PMID: 24602919. DOI: 10.4244/EIJV11I2A32.

20. Yan B, Yang J, Fan Y, Zhao B, Ma Q, Yang L, Ma X. Association of coronary dominance with the severity of coronary artery disease: a crosssectional study in Shaanxi Province, China. BMJ open. 2018 Nov 1;8(11):e021292. DOI: 10.1136/bmjopen-2017-021292 